RESEARCH REPORT

\title{
Wider income gaps, wider waistbands? An ecological study of obesity and income inequality
}

\author{
Kate E Pickett, Shona Kelly, Eric Brunner, Tim Lobstein, Richard G Wilkinson
}

J Epidemiol Community Health 2005;59:670-674. doi: 10.1136/jech.2004.028795

See end of article for authors' affiliations .....................

Correspondence to: Dr K E Pickett, Department of Health Sciences, University of York, Seebohm Rowntree Building, Area 3, Heslington, York YO10 5DD, UK; kp6@york.ac.uk

Accepted for publication 15 February 2005

\begin{abstract}
Objectives: To see if obesity, deaths from diabetes, and daily calorie intake are associated with income inequality among developed countries.

Design: Ecological study of 21 developed countries.

Countries: Countries were eligible for inclusion if they were among the top 50 countries with the highest gross national income per capita by purchasing power parity in 2002, had a population over 3 million, and had available data on income inequality and outcome measures.

Main outcome measures: Percentage of obese (body mass index $>30$ ) adult men and women, diabetes mortality rates, and calorie consumption per capita per day.

Results: Adjusting for gross national per capita income, income inequality was positively correlated with the percentage of obese men $(r=0.48, p=0.03)$, the percentage of obese women $(r=0.62, p=0.003)$, diabetes mortality rates per 1 million people $(r=0.46, p=0.04)$, and average calories per capita per day $(r=0.50, p=0.02)$. Correlations were stronger if analyses were weighted for population size. The effect of income inequality on female obesity was independent of average calorie intake.

Conclusions: Obesity, diabetes mortality, and calorie consumption were associated with income inequality in developed countries. Increased nutritional problems may be a consequence of the psychosocial impact of living in a more hierarchical society.
\end{abstract}

obesity in the United States of America and the low rates among the Scandinavian countries, she suggested that income inequality plays a causal part, a statement that has attracted considerable controversy.

Income inequality has been associated with numerous negative health and psychosocial outcomes, such as lower life expectancy, higher homicide rates, and lower self rated health. ${ }^{14}$ The psychosocial stress of life near the bottom of a steeply hierarchical society is a suggested explanation for these associations. We decided to test whether income inequality is associated with increased rates of obesity and to look at associations with one of its causes-higher calorie consumption-and one of its consequences-diabetes mortality-in developed countries.

\section{METHODS}

Eligibility criteria for inclusion in this study were: being among the top 50 countries with the highest gross national income (GNI) per capita by purchasing power parity in 2002 (range: \$10 820-\$36 690); having population over 3 million (to exclude tax havens such as the Cayman Islands); having available data on income inequality, and population based estimates of obesity prevalence for 1990 or later. There were 21 eligible countries: Australia, Austria, Belgium, Canada, Denmark, Finland, France, Germany, Greece, Ireland, Italy, Japan, Netherlands, New Zealand, Norway, Portugal, Spain, Sweden, Switzerland, the UK, and the USA.

\section{Income inequality}

Data on income inequality came from the United Nations Development Program Human Development Indicators. ${ }^{15}$ Income inequality was measured as the ratio of the income share of the richest $20 \%$ of the population to the income share of the poorest $20 \%$ in the 1990s. The ratio ranged from 3.4 in Japan, the most equal country, to 9.0 in the USA, the

Abbreviations: $\mathrm{BMI}$, body mass index; $\mathrm{GNI}$, gross national income all except five. As Polly Toynbee wrote in a recent Guardian article: "Fat is a class issue" ${ }^{13}$ Pointing to the high rates of 


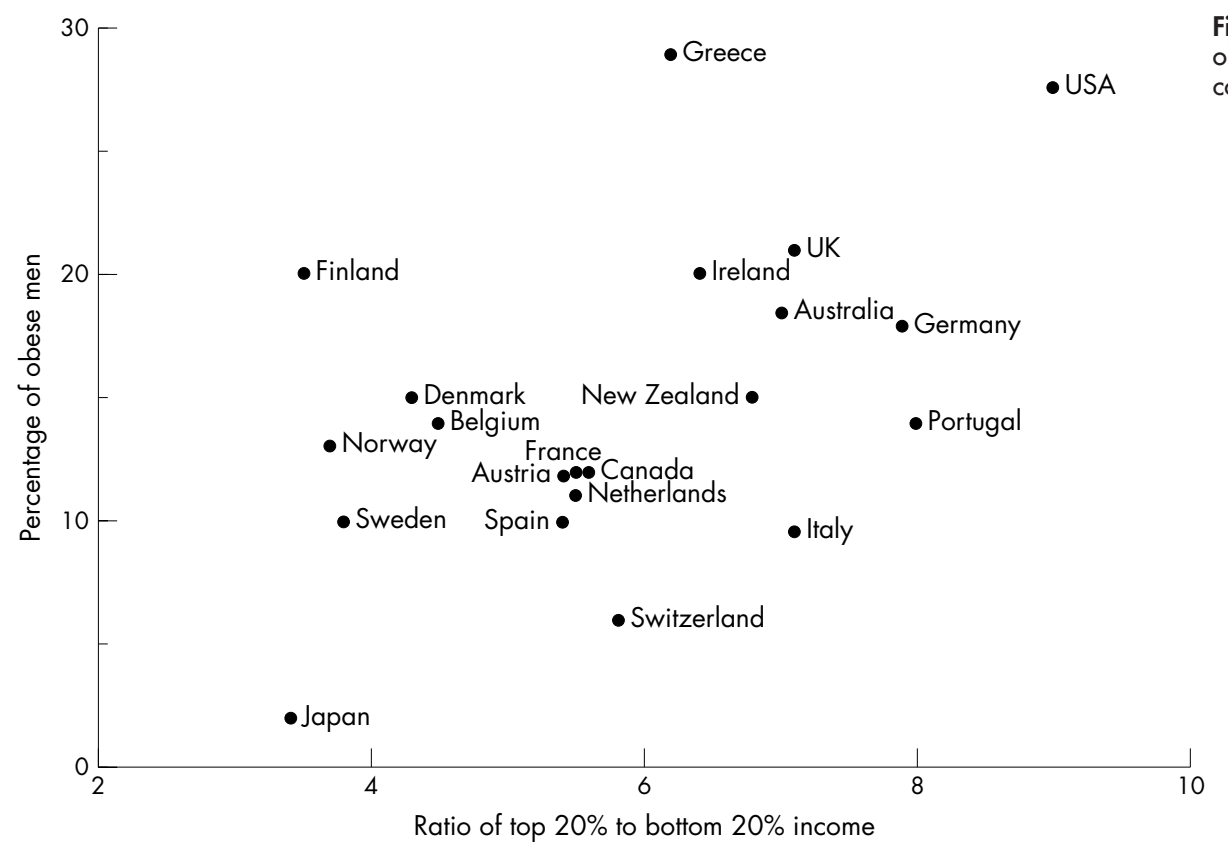

Figure 1 The relation between male obesity and income inequality in 21 rich countries.

most unequal. Gini coefficients of inequality from the same source were also investigated. The Gini coefficient is a measure of income inequality that varies between 0 (equality) and 1 (maximum inequality). ${ }^{16}$

\section{Outcomes}

Data on the proportion of the male and female population who are obese (BMI >30) came from the International Obesity TaskForce, an organisation of the International Association for the Study of Obesity. ${ }^{17}$ Diabetes mellitus mortality rates per 1 million population came from the World Health Organisation Mortality Database. ${ }^{18}$ The extent to which diabetes is identified as a cause of death depends on medical orthodoxy, however the WHO makes adjustments to mortality data to account for incompleteness and miscoding. Calorie intake per capita per day came from the Organisation for Economic Co-operation and Development (OECD) Health Database. ${ }^{19}$ The calorie intake data are population averages, for most countries the time series begins in the early 1980s and runs through the late 1990s. We chose to examine diabetes mortality, in addition to obesity, to establish the coherence of any association with income inequality, and caloric intake as an indicator of a possible mechanism. Although diabetes mortality includes deaths from type I

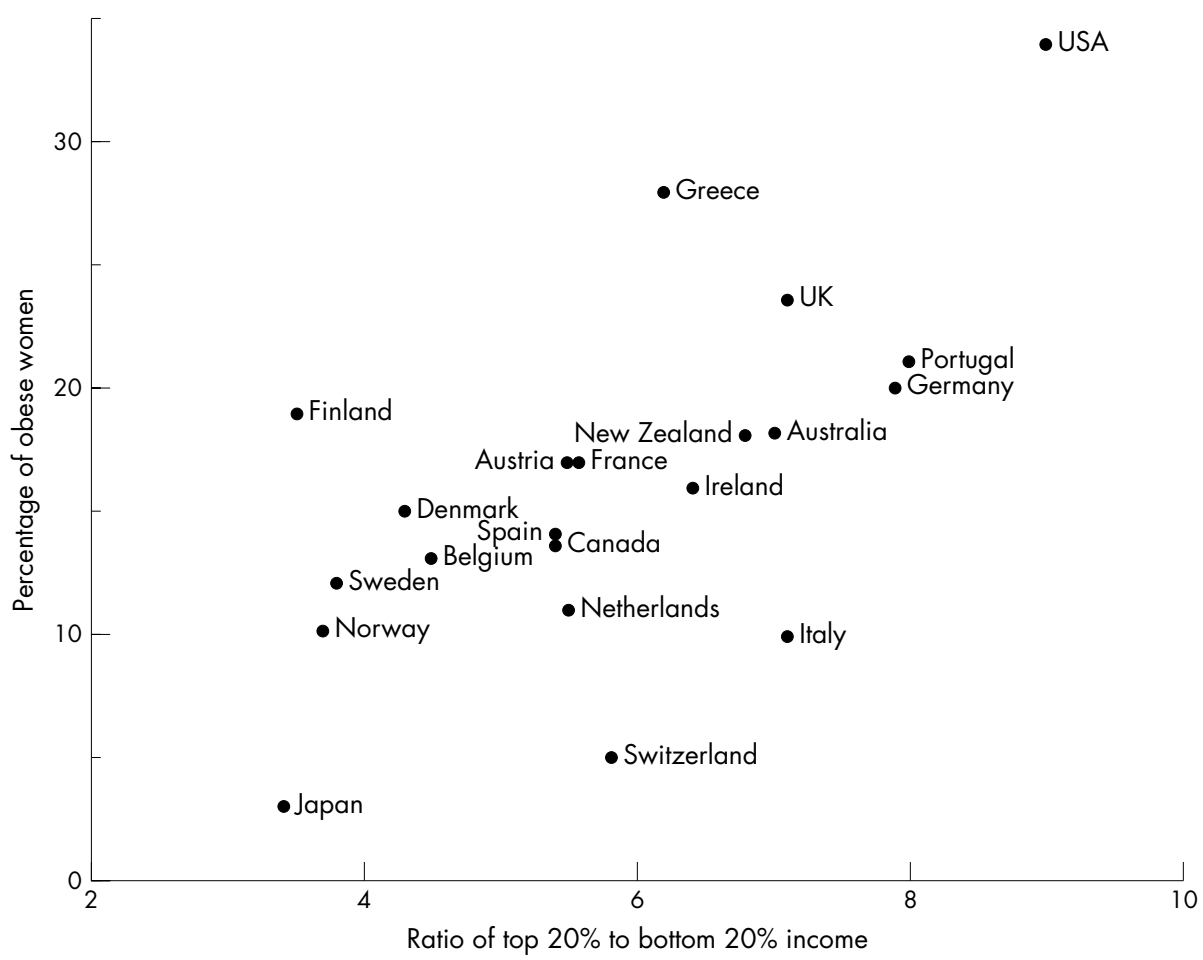

The relation between female obesity and income inequality in 21 rich countries. 
diabetes, which is less associated with obesity than type II diabetes, diabetes mortality rates are more directly related to obesity than deaths from other causes consequential to obesity, such as cardiovascular disease, which has a more complex aetiology.

\section{Per capita income}

GNI per capita (converted to US dollars using "purchasing power parities" to reflect price differences) was drawn from the World Bank World Development Indicators. ${ }^{20}$

\section{Statistical methods}

We computed Pearson correlation coefficients to measure the associations between income inequality and obesity, diabetes mortality, and calorie intake, adjusting for GNI per capita. Primary results are presented unweighted for population size. We also present population weighted analyses. Multiple linear regression models were used to estimate the magnitude of associations between income inequality and obesity and diabetes mortality, as well as to examine whether or not calorie intake mediated any relation between income inequality and obesity. All models adjusted for absolute income per capita (GNI per capita) and those that included obesity were sex specific.

\section{RESULTS}

The percentage of obese men in the population ranged from $1.9 \%$ in Japan to $29 \%$ in Greece, with a mean of $14.9 \%$ $(\mathrm{SD}=6.4)$. For women, Japan had the lowest percentage of obese women, $2.9 \%$, and the USA had the highest, $34 \%$, with a mean of $16.0 \%(S D=6.9)$. Diabetes mortality rates per million persons ranged from 55 in Greece, to 316 in Italy; the mean was $182(\mathrm{SD}=70)$. Calories per capita per day were lowest in Japan (2767) and highest in Austria (3753), with a mean of $3395(\mathrm{SD}=254)$.

The Pearson correlation coefficients we present first are for the unweighted analyses, with the results for the weighted analyses presented in parentheses. The correlation between income inequality and male obesity was $0.48, \mathrm{p}=0.03$ (weighted $r=0.84, \mathrm{p}<0.001$ ), see figure 1. For female obesity the correlation was $0.62, \mathrm{p}=0.003$ (weighted $r=0.85$, $\mathrm{p}<0.001$ ), see figure 2 . The correlation for income inequality and diabetes mortality rate was $0.46, p=0.04$ (weighted $r=0.79, \mathrm{p}<0.001)$ and for income inequality and calorie intake per capita per day it was $0.50, \mathrm{p}=0.02$ (weighted $r=0.69, \mathrm{p}=0.001$ ). Results were similar if the Gini coefficient was used instead of the ratio of the top 20\% to the bottom $20 \%$ of income.

In the multiple linear regression analyses the effects of income inequality on obesity were attenuated by calories per capita per day but unaffected by GNI per capita. However, among women, but not among men, and in all weighted analyses, income inequality remained statistically significantly associated with obesity. In these models, GNI per

\section{What is already known on this topic}

- Although many studies have shown that more unequal societies tend to have worse health this remains a controversial issue.

- In developed countries rates of obesity are highest among the poor and social gradients are becoming steeper.

- Relations have been reported between income inequality and abdominal weight gain in men and higher BMI in women in the 50 USA states

\section{What this study adds}

- The proportion of the population with $\mathrm{BMI}>30$ is related to income inequality across 21 developed countries among both men and women.

- The prevalence of obesity within developed countries is unrelated to average income.

- The association between income inequality and obesity is independent of calorie intake per capita in women.

- The psychosocial effects of social position or relative income may contribute to behavioural and/or physiological processes leading to obesity.

capita was not significantly associated with either male or female obesity. In unweighted analyses, for every unit increase in the ratio of the top $20 \%$ to the bottom $20 \%$ of income the percentage of obese men in the population increased by $1.34 \%(2.97 \%$ in weighted model $)$ and the percentage of obese women rose by $2.10 \%$ (3.25\% in weighted model).

\section{DISCUSSION}

Among developed countries for which data are available, income inequality was significantly related to obesity among men and women, diabetes mortality and average calorie intake, both before and after controlling for GNI per capita, whether or not countries were weighted for population size. Controlling for calorie intake attenuated the association between income inequality and obesity, particularly among men.

Although we are unaware of other international studies of income inequality and obesity, our findings are consistent with studies within the USA, which have shown associations between state level income inequality and abdominal weight gain in men, ${ }^{21}$ odds of sedentary lifestyles among both men and women and higher BMI among women. ${ }^{22}$ In the latter study, BMI among the poor was particularly associated with income inequality.

\section{Strengths and weaknesses of the study}

Strengths of this study include the large number of developed countries and the systematic application of inclusion criteria. The potential confounding effect of absolute income levels is an unlikely explanation of our findings, as we adjusted analyses for GNI per capita. The parallel relations between income inequality and both average calorie intake (a contributor to obesity) and diabetes mortality (a consequence of obesity) increases confidence that the association between income inequality and obesity is real.

Nevertheless, our study has some limitations. Societal variables, such as income inequality, require analysis at an ecological level. In our study we are addressing the question of whether or not societies with wider income differences have higher population rates of obesity. Given adequate data, a multilevel longitudinal analysis would allow for the

\section{Policy implications}

Public policies promoting greater equality and reducing the burden of low social status may make an important contribution to reducing and preventing obesity. Relative deprivation may influence the effectiveness of policies designed to promote good nutrition and physical activity. 
separation of societal and individual influences on obesity and provide more insight into possible causal processes.

Although we have used the most comprehensive source of international data on obesity, based on nationally representative samples, data collected in different countries may vary in quality and limit the generalisability of our study. The same is true for data on per capita daily calorie consumption. However, we have no reason to suspect that measurement error in these variables would vary systematically with income inequality, (although they might well vary systematically with levels of GNI per capita), and therefore our findings are likely to be conservative, rather than inflated.

Central obesity (high waist:hip ratio) particularly has been linked to poor health outcomes and chronic stress is a risk factor for this pattern of fat distribution. Without data on waist:hip ratio we were unable to examine this aspect of obesity in our study and it remains an interesting area for future research.

\section{Interpretation}

Our results and previous research ${ }^{22}$ suggest that the pathways relating obesity to inequality are likely to include total calorie intake and physical activity. In addition there may be direct psychosocial effects on central obesity and it is possible that the nutritional composition of the foodstuffs providing the calories may play a part. However, the psychosocial effects of inequality may be particularly important because they can influence all other pathways: sedentarism, calorie intake, food choice, and the physiological effects of stress.

In the MONICA study the social gradient in obesity has increased in almost all countries between 1979 and 1996. ${ }^{12}$ Interestingly, of the 11 countries included in both our study and the MONICA study; the USA had the steepest social gradient in obesity and greatest income inequality, and Sweden the smallest of each. The relation between obesity and income inequality, coupled with the evidence of an increasing tendency for obesity rates to be highest among the poor, suggests that psychosocial factors related to social position or relative income may be more important than absolute living standards. The fact that the relation between income inequality and obesity is stronger among women than among men in our study is paralleled by findings among the 50 states of the $\mathrm{USA}^{22}$ and the more consistent social gradient in obesity among women than men found in the MONICA data. ${ }^{12}$

This raises the familiar issue of the merits of individual compared with societal approaches to health. Underlying any interpretation of the influence of inequality must be the "obesogenic" environment of lower levels of physical activity and the wider availability of cheap, energy dense foods ${ }^{6}{ }^{23}$ that seem to overwhelm normal appetite controls. ${ }^{24}$ Although structural factors involving the promotion and pricing of such foods are likely to partially explain the social distribution of obesity, it is not clear that these will vary with income inequality. Given that there are social gradients not only in diet and exercise, ${ }^{10}$ but also in other health related behaviours as well as in a range of social problems associated with relative deprivation-such as violence, teenage pregnancy, and poor educational performance-there is an explanatory choice to be made. Should we look for quite separate explanations for the social gradient in each, or does low social status have psychosocial effects that contribute to the gradient in many different outcomes? Low social status is for instance likely to increase anxiety and stress levels and to reduce people's ability to exercise control over their lives. ${ }^{25}$ If greater inequality deepened or broadened such effects-as some of the evidence suggests ${ }^{26}$-many of the associated problems would also be exacerbated. ${ }^{14}$
The US surgeon general has called for a multifaceted public health approach to obesity prevention that focuses "on health rather than appearance" and empowers individuals and communities to "address barriers, reduce stigmatization". ${ }^{27}$ What he means is that there is a societal responsibility to provide safe, accessible opportunities for physical activity, healthy food choices and PE in schools, to promote breast feeding and nutrition education. The International Obesity TaskForce has called for a similar approach to be adopted in Europe. ${ }^{2}$ What these approaches overlook are the reasons why people continue to live a sedentary lifestyle and to eat an unhealthy diet, and how these behaviours provide comfort.

Because the behaviour changes needed to improve health or reduce obesity are easier for people who feel in control and in good psychosocial condition ${ }^{28}$ lessening the burdens of low social status and relative poverty may make an important contribution both to better health and to a reduction of obesity.

Governments cannot avoid influencing income distribution, for better or worse, through a wide range of policies, including taxes and benefits, management of the national economy, unemployment levels, education policies, minimum wages, and so on. Policies that promote equality may be just as vital for public health as those that promote economic growth. Public policies designed to improve nutrition education and healthy food choice, tackle food labelling and marketing, school meals, transport policies, and opportunities for exercise may work best when supported by policies to promote greater equality.

\section{Authors' affiliations}

K E Pickett, Department of Health Sciences, University of York, UK S Kelly, R G Wilkinson, Division of Epidemiology and Public Health, University of Nottingham, UK

E Brunner, Department of Epidemiology and Public Health, University College London, UK

T Lobstein, International Obesity TaskForce, UK

Funding: none.

Competing interests: none.

Ethics approval: no ethical approval was needed for this ecological study.

\section{REFERENCES}

1 Flegal KM, Carroll MD, Ogden CL, et al. Prevalence and trends in obesity among US adults. JAMA 2002;288:1723-7.

2 International Obesity TaskForce. Obesity in Europe. London: International Obesity TaskForce in collaboration with the European Association for the Study of Obesity Task Forces, 2002.

3 World Health Organisation. Report of a joint WHO/FAO expert consultation. Diet, nutrition and the prevention of chronic diseases. Geneva: WHO, 2002.

4 Nishida C, Uauy R, Kumanyika S, et al. The joint WHO/FAO Expert Consultation on diet, nutrition and the prevention of chronic diseases: process, product and policy implications. Public Health Nutr 2004;7:245-50.

5 Kimm SY, Obarzanek E, Barton BA, et al. Race, socioeconomic status, and obesity in 9- to 10-year-old girls: the NHLBI growth and health study. Ann Epidemiol 1996;6:266-75.

6 Lobstein T, Baur L, Uauy R. Obesity in children and young people: a crisis in public health. Obes Rev 2004;5(suppl. 1):4-85

7 Bjorntorp P. Do stress reactions cause abdominal obesity and comorbidities? Obes Rev 2001:2:73-86.

8 Dallman MF, Pecoraro N, Akana SF, et al. Chronic stress and obesity: a new view of "comfort food". Proc Natl Acad Sci U S A 2003;100:11696-701.

9 Drapeau V, Therrien F, Richard D, et al. Is visceral obesity a physiological adaptation to stress? Panminerva Med 2003;45:189-95.

10 Brunner $E$, Juneja $M$, Marmot $M$. Abdominal obesity and disease are linked to social position. BMJ 1998;316:308

11 Pena M, Bacallao J, eds. Obesity and poverty: a new public health challenge. Washington: Pan American Health Organisation, 2000.

12 Molarius A, Seidell JC, Sans S, et al. Educational level, relative body weight and changes in their association over 10 years: An international perspective from the WHO MONICA project. Am J Public Health 2000;90:1260-86.

13 Toynbee P. Inequality is fattening. Guardian 2004; May 28.

14 Wilkinson RG. The impact of inequality. New York: New Press, 2005.

15 United Nations Development Program. Human development report. New York: Oxford University Press, 2003. 
16 Subramanian SV Kawachi I. Income inequality and health: What have we learned so far? Epidemiol Rev 2004;26:78-91.

17 International Obesity TaskForce. Overweight and obese. London International Obesity Taskforce, 2002

18 World Health Organisation Statistical Information System (WHOSIS) Mortality database. Geneva: WHO, 2003.

19 Organisation for Economic Co-operation and Development. OECD health data. 3rd ed. Paris: OECD, 2003.

20 World Bank. World Development Indicators database. New York: World Bank, 2004.

21 Kahn HS, Tatham LM, Pamuk ER, et al. Are geographic regions with high income inequality associated with risk of abdominal weight gain? Soc Sci Med 1998;47:1-6.

22 Diez Roux AV, Link BG, Northridge ME. A multilevel analysis of income inequality and cardiovascular disease risk factors. Soc Sci Med 2000;50:673-87.
23 Nielsen SJ, Siega-Riz AM, Popkin BM. Trends in energy intake in US between 1977 and 1996: similar shifts seen across age groups. Obes Res 2002; 10:370-8

24 Prentice AM, Jebb SA. Fast foods, energy density and obesity: a possible mechanistic link. Obes Rev 2003:4:187-94.

25 Marmot M. Status syndrome: how your social standing directly affects your health and life expectancy. London: Bloomsbury, 2004.

26 Pickett KE, Mookherjee J, Wilkinson RG. Teenage births and violence are related to income inequality among rich countries. Am J Public Health (in press).

27 US Department of Health and Human Services. The surgeon general's call to action to prevent and decrease overweight and obesity. Rockville, MD: Office of the Surgeon General, US Department of Health and Human Services, 2001.

28 Goodman E. Letting the "Gini" out of the bottle: Social causation and the obesity epidemic. J Pediatr 2003;142:228-30.

\section{Clinical Evidence-Call for contributors}

Clinical Evidence is a regularly updated evidence-based journal available worldwide both as a paper version and on the internet. Clinical Evidence needs to recruit a number of new contributors. Contributors are healthcare professionals or epidemiologists with experience in evidence-based medicine and the ability to write in a concise and structured way.

Areas for which we are currently seeking authors:

- Child health: nocturnal enuresis

- Eye disorders: bacterial conjunctivitis

- Male health: prostate cancer (metastatic)

- Women's health: pre-menstrual syndrome; pyelonephritis in non-pregnant women

However, we are always looking for others, so do not let this list discourage you.

Being a contributor involves:

- Selecting from a validated, screened search (performed by in-house Information Specialists) epidemiologically sound studies for inclusion.

- Documenting your decisions about which studies to include on an inclusion and exclusion form, which we keep on file.

- Writing the text to a highly structured template (about 1500-3000 words), using evidence from the final studies chosen, within 8-10 weeks of receiving the literature search.

- Working with Clinical Evidence editors to ensure that the final text meets epidemiological and style standards.

- Updating the text every six months using any new, sound evidence that becomes available. The Clinical Evidence in-house team will conduct the searches for contributors; your task is simply to filter out high quality studies and incorporate them in the existing text.

- To expand the topic to include a new question about once every 12-18 months.

If you would like to become a contributor for Clinical Evidence or require more information about what this involves please send your contact details and a copy of your CV, clearly stating the clinical area you are interested in, to Klara Brunnhuber (kbrunnhuber@ bmigroup.com).

\section{Call for peer reviewers}

Clinical Evidence also needs to recruit a number of new peer reviewers specifically with an interest in the clinical areas stated above, and also others related to general practice. Peer reviewers are healthcare professionals or epidemiologists with experience in evidence-based medicine. As a peer reviewer you would be asked for your views on the clinical relevance, validity, and accessibility of specific topics within the journal, and their usefulness to the intended audience (international generalists and healthcare professionals, possibly with limited statistical knowledge). Topics are usually 1500-3000 words in length and we would ask you to review between 2-5 topics per year. The peer review process takes place throughout the year, and our turnaround time for each review is ideally 10-14 days.

If you are interested in becoming a peer reviewer for Clinical Evidence, please complete the peer review questionnaire at www.clinicalevidence.com or contact Klara Brunnhuber (kbrunnhuber@bmigroup.com). 